International Journal of Linguistics, Literature and Translation

ISSN: 2617-0299 (Online); ISSN: 2708-0099 (Print)

DOI: $10.32996 /$ ijltt

Journal Homepage: www.al-kindipublisher.com/index.php/ijltt

\title{
Derivational Morphemes in Guihulngan-Visayan
}

\author{
John Carlo R. Perez 8 (D) $ه$ \\ Faculty, English and Literature Department, Negros Oriental State University, Guihulngan City, Philippines \\ $\triangle$ Corresponding Author: Author's Name, John Carlo R. Perez, E-mail: przjohncarlo@gmail.com
}

\section{ARTICLE INFORMATION}

Received: June 08, 2021

Accepted: July 11, 2021

Volume: 4

Issue: 7

DOI: $10.32996 /$ ijllt.2021.4.7.6

\section{KEYWORDS}

Derivational, Guihulngan, Infix, Morphemes, Prefix, Suffix, Visayan

\section{ABSTRACT}

Studies indicate that morphology is vital in examining word systems to understand a specific language better. Morphology helps in assessing the internal structure to discover natural language and linguistics. This study employs a mixed-method design that gives a quantitative analysis of the derivational morphemes and a qualitative approach that examines the corpora made by second-year college students to understand the meanings and functions of derivational morphemes of the Visayan language, specifically the Guihulngan-Visayan because it is believed that word structures and processes can provide an efficient relationship between speakers. Although Guihulngan-Visayan is not an established dialect, significant research proved that the Visayan language is composed of different dialects unique to every place. This present study aims to uncover the features and to distinguish the characteristics of the dialect. After careful analysis of the author and the meticulous attention of the inter-raters, it was revealed that the derivative morphemes used include prefixes, infixes, and suffixes, which shows that the language has contained varied and exciting morphological methods that could influence the message of a speaker, considering that it is 'divided between grammar and lexicon.' In summary, these kinds of morphemes should not be generalized; instead, critical understanding of the dialect should always be given priority to show proficiency and appropriate communication.

\section{Introduction}

Language is an essential and ultimate instrument of communication required for language learners and everyone to communicate effectively. This vital part of learning enables everyone to understand the main contents, such as vocabulary, sentence structure, and grammar. In this sense, morphology becomes fundamental in studying word structures to elicit more profound knowledge of a specific language.

This study focuses on the forms and meanings of derivational morphemes of the Visayan language, most specifically the Guihulngan-Visayan dialect, which are often amisunderstood by speakers. Considering that rules in the Visayan language differ based on the geographical location, especially on the proper use of word structures, this study would further understand the morphological process of derivational morphemes.

Guihulngan is a small city in the province of Negros Oriental located on the northern side of Dumaguete City. Cebuano/ Visayan language is mainly spoken by the people living here and its neighboring cities and municipalities, which means that morphological processes are similar or closely related. Abid et al. (2020) revealed dimensions caused by the derivational

\section{K C AL-KINDI CENTER R D FOR RESEARCH AND} Your gateway to world-class research

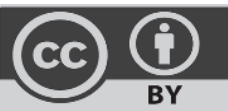

Published by Al-Kindi Center for Research and Development, London, United Kingdom. Copyright (c) the author(s). This open access article is distributed under a Creative Commons Attribution (CC-BY) 4.0 license 
morphemes when attached with other morphemes. Suppose the derivational morpheme is attached with a free morpheme. It will convey a different meaning, and a chance has that it will change even word class.

This study specifically seeks to answer the following research question:

1. What are the different derivational morphemes used in Guihulngan Visayan based on the essays?

2. What are the meanings and functions of each derivational morpheme?

This analysis is focused primarily on the Booij (2017) theory of building morphology, which deals with the vocabulary structure. It is studied as constructions in which tricky words of the language systematically combined with form and meanings are studied. According to Masini and Audring (2019), the idea is that the fundamental concept of Construction Grammar considers shapemeaning pairs ("constructions") rather than distinctions between grammar and lexicon as basic units of an expression.

\section{Literature Review}

Morphology is performed to decide how words are shaped and their inner structures while learning a natural language or linguistics (Aronoff, 2005). In essence, a morpheme reflects the minimum unit of meaning or grammar that demonstrates the tense value of a word or the appetite used. The analysis of primary forms of language is, therefore, morphology. Two forms of morphemes exist, free morphemes that can stand as single words and bound morphemes, which are not usually alone and generally attached to another shape.

Kilaton (2011) showed Cebuano as the second most commonly spoken language in the Philippines after Tagalog, being spoken by some 20 million people in Cebu, Bohol, Negros, and Mindanao. It is also imperative to research and illustrate the morphology of terms because it helps explain illustrations and guidelines for spelling and discovering the meanings of unfamiliar words.

Bodily and Lonsdale (2014) showed that it is crucial for language acknowledgments, Web searches, and corpus analysis to understand how words are created and figure out all instances of words, including all contaminated words, based on each word found. This research explores the forms and interpretations of derived morphemes based on essays by students in English in their second year of significance. Analysis of word structures and uses can provide efficient contact between speakers.

\section{Methodology}

This paper used a mixed-methods research design in exploring the corpus made by the second-year Bachelor of Secondary Education major in English students at Negros Oriental State University - Guihulngan Campus. The descriptive method was used to determine the number of morphemes used in the essays. A qualitative method was employed to understand the meanings and functions of the derivational morphemes. Students were tasked to make a three-paragraph essay, with at least three sentences for each paragraph, regarding their life experiences written in Guihulngan-Visayan.

The data were analyzed using frequency count and percentage count to answer the statement of problem number 1. At the same time, a textual analysis was employed to thoroughly understand each morpheme's meanings and functions to answer problem number 2. Textual analysis is a methodology that involves understanding language, especially in derivational morphology. The researcher has used the Information Extraction technique throughout from textual analysis. The textual analysis consists of analyzing the content and the structure or design of a text and how elements function, often as part of a larger context. This type of analysis was evaluated correctly by the peer evaluators so that comprehensive and quality data analysis would be provided to understand the language's content thoroughly.

This research identified the Guihulngan-Visayan morphemes collected from the source data in the preliminary stage of data collection. In the second stage of Information Extraction, the data were analyzed individually to identify the changes that happen in the word processes. In the third stage of interpreting, the data found the derivational morpheme. After discovering the forms and meanings of the derivational morphemes in Guihulngan Visayan, the conclusion is the last stage used to answer the research question and achieve the study's objectives.

\section{Results and Discussion}

After identifying and evaluating the derivational morphemes found in the essays, the researcher then tallied each morpheme and classified it as prefix, infix, and suffix. Repeated words were only counted once so that it would be easier to determine how 
they were used. The study shows two significant sections: Part A shows the frequency and percentage counts of the morphemes, and Part $B$ includes the textual analysis to discover the meaning and functions of the derivational morphemes.

\section{A. Derivational Morphemes found in the Corpus}

The derivational morphemes used in Guihulngan-Visayan were identified as prefixes, suffixes, and infixes. All these are used differently and appeared in the corpus and essential elements in understanding the specific language. The result for this section is presented in tables one, two, and three. The tables below would comprehensively explain how the derivational morphemes function to produce meaningful words to answer the research questions.

Table 1: Derivational Morphemes used as Prefixes

\begin{tabular}{|c|c|c|c|c|c|}
\hline Derivational Morphemes & Count & Percentage & Derivational Morphemes & Count & Percentage \\
\hline ga- & 19 & $2.59 \%$ & mi- & 14 & $1.91 \%$ \\
\hline gi- & 55 & $7.49 \%$ & mu- & 35 & $4.77 \%$ \\
\hline gika- & 2 & $0.27 \%$ & mupa- & 1 & $0.14 \%$ \\
\hline gina- & 5 & $0.68 \%$ & na- & 60 & $8.17 \%$ \\
\hline gipa- & 6 & $0.82 \%$ & nag- & 33 & $4.50 \%$ \\
\hline gipang- & 2 & $0.27 \%$ & naga- & 7 & $0.95 \%$ \\
\hline ha- & 1 & $0.14 \%$ & nagka- & 4 & $0.54 \%$ \\
\hline hi- & 3 & $0.41 \%$ & nagpa- & 8 & $1.09 \%$ \\
\hline i- & 5 & $0.68 \%$ & nahi- & 4 & $0.54 \%$ \\
\hline ig- & 1 & $0.14 \%$ & naka- & 21 & $2.86 \%$ \\
\hline $\mathrm{ik}-$ & 1 & $0.14 \%$ & nang- & 2 & $0.27 \%$ \\
\hline ika- & 7 & $0.95 \%$ & naning- & 2 & $0.27 \%$ \\
\hline ikapa- & 1 & $0.14 \%$ & ni- & 19 & $2.59 \%$ \\
\hline im- & 1 & $0.14 \%$ & ning- & 2 & $0.27 \%$ \\
\hline in- & 4 & $0.54 \%$ & pa- & 23 & $3.13 \%$ \\
\hline ipa- & 1 & $0.14 \%$ & pag- & 63 & $8.58 \%$ \\
\hline ka- & 75 & $10.20 \%$ & paga- & 3 & $0.41 \%$ \\
\hline kada- & 3 & $0.41 \%$ & paghi- & 1 & $0.14 \%$ \\
\hline kaga- & 1 & $0.14 \%$ & pagka- & 8 & $1.09 \%$ \\
\hline kama- & 2 & $0.27 \%$ & pagpa- & 8 & $1.09 \%$ \\
\hline kani- & 2 & $0.27 \%$ & pakig- & 2 & $0.27 \%$ \\
\hline kina- & 5 & $0.68 \%$ & pama- & 1 & $0.14 \%$ \\
\hline luma- & 1 & $0.14 \%$ & pang- & 9 & $1.23 \%$ \\
\hline ma- & 95 & $12.9 \%$ & pasi- & 1 & $0.14 \%$ \\
\hline mag- & 29 & $3.95 \%$ & pi- & 1 & $0.14 \%$ \\
\hline maga- & 1 & $0.14 \%$ & pina- & 2 & $0.27 \%$ \\
\hline magka- & 2 & $0.27 \%$ & pinaka- & 3 & $0.41 \%$ \\
\hline magma- & 1 & $0.14 \%$ & ra- & 1 & $0.14 \%$ \\
\hline magpa- & 7 & $0.95 \%$ & su- & 1 & $0.14 \%$ \\
\hline magpaka- & 1 & $0.14 \%$ & tag- & 1 & $0.14 \%$ \\
\hline mahi- & 2 & $0.27 \%$ & ti- & 2 & $0.27 \%$ \\
\hline maka- & 32 & $4.36 \%$ & tig- & 4 & $0.54 \%$ \\
\hline makapa- & 1 & $0.14 \%$ & uma- & 1 & $0.14 \%$ \\
\hline makig- & 2 & $0.27 \%$ & & & \\
\hline mama- & 2 & $0.27 \%$ & & & \\
\hline
\end{tabular}




$\begin{array}{lll}\text { mang- } & 4 & 0.54 \% \\ \text { mapa- } & 3 & 0.41 \% \\ \text { matag- } & 2 & 0.27 \%\end{array}$

The table shows that the frequently used prefixes were ma-, ka-, and pag- having 12.9\%, 10.20\%, and $8.58 \%$, respectively. On the other hand, prefixes ha-, ig-, ik-, im-, luma-, maga-, magma-, magpaka-, mupa-, paghi-, pama-, pasi-, pi-, ra-, su-, tag, and um- only occurred once. The data entails that prefixes are always present in the language; thus, distinguishing the proper use of these prefixes is vital for building effective communication or becoming an active reader. Firat (2006) emphasizes that prefixes, like suffixes and infixes, must be handled carefully because they have an essential role in the word-forming mechanism. Therefore, they should not be confused and given maximum impotence.

Table 2: Derivational Morphemes used as Infixes

\begin{tabular}{llllll}
\hline Derivational Morphemes & Count & Percentage & Derivational Morphemes & Count & Percentage \\
-hi- & 8 & $32.00 \%$ & - lu- & $4.00 \%$ & 1 \\
-in- & 11 & $44.00 \%$ & - um- & $4.00 \%$ & \\
-la- & 1 & $4.00 \%$ & & $\mathbf{2 5}$ & $\mathbf{1 0 0} \%$ \\
& & & TOTAL & & \\
\hline
\end{tabular}

Table 2 divulges the infixes used in the essay. The infix -in- was used 11 times or $44.00 \%$ based on the study's corpus, while infixes -la- and -lu- were used once. It is also observable that there were really few infixes used. Guihulngan-Visayan is usually within the base form of a word, rather than the initial or final part to make new words and deepen meanings. It has been stated by Beljan (2015) that the main aim of this infixation is not to establish words or concepts in morphology but stylistic and descriptive terms.

Table 3

Derivational Morphemes used as Suffixes

\begin{tabular}{llllll}
\hline Derivational Morphemes & Count & Percentage & Derivational Morphemes & Count & Percentage \\
\hline -a & 9 & $3.17 \%$ & - ng & 68 & $23.90 \%$ \\
-an & 86 & $30.30 \%$ & - nong & 2 & $0.70 \%$ \\
-anan & 1 & $0.35 \%$ & - on & 41 & $14.40 \%$ \\
-ang & 2 & $0.70 \%$ & - ong & 4 & $1.41 \%$ \\
-ay & 4 & $1.41 \%$ & - s & 1 & $0.35 \%$ \\
-g & 24 & $8.45 \%$ & - so & 1 & $0.35 \%$ \\
-ha & 3 & $1.06 \%$ & $-y$ & 9 & $3.17 \%$ \\
-han & 22 & $7.75 \%$ & & & $\mathbf{2 8 5}$ \\
-i & 3 & $1.06 \%$ & TOTAL & & $\mathbf{1 0 0} \%$ \\
\end{tabular}

Table 3 reveals that -an, -ng, and -on were the derivational morphemes used as repeated suffixes with $30.30 \%, 23.90 \%$, and $14.40 \%$, respectively. While suffixes -anan, $\mathbf{- s}, \mathbf{- y}$ were the least used morphemes because they were only used once. Suffixes are attached to the end of words that contain the strong impact of a word's effect. Manova (2015) has clarified that there is evidence of suffixes for closure in various languages. However, it is challenging to identify semantic processes affecting a word. This shows that a detailed understanding of morphological processes will help students and speakers acquire knowledge of the language and better understand it. 


\section{B. The Meanings and Functions of Derivational Morphemes}

This section elaborates a better understanding of the derivational morphemes found in the corpus. The meaning identifies the conceptual definition of each morpheme, and the function presents the usage or the operational definition of the words. It could be noted that there are provided examples to evaluate the individual characteristics of the words correctly.

\section{B.1. Meaning and Functions of Prefixes}

This part exemplifies the distinguishing characteristics of derivational morphemes, which were used as prefixes. The observable in Guihulngan-Visayan prefixes are as follows:

Prefix: ga-

Definition: denotes an action that is presently happening

Function: functions as a verb when attached to words

Example: gahulat (waiting), galakaw (walking)

Prefix: gi-

Definition: denotes an action that happens in the past

Function: functions as a verb when attached to words

Example: gidala (brought), gidawat (received)

Prefix: gika-

Definition: a combination of prefixes gi- and ka- that expresses a past perfect tense

Function: functions as an adjective when attached to words Example: gikahimut-an (had been wished of), gikaluhaan (had been cried of)

Prefix: gina-

Definition: a combination of prefixes gi- and na- that expresses an action in the past is still happening in the present

Function: functions as an adjective when attached to words Example: ginabatyag (have been feeling), ginapangita (have been looking off)

Prefix: gipa-

Definition: a combination of prefixes gi- and pa- that tells something is done or tasked to someone

Function: functions as a verb when attached to words Example: gipainom (was told to drink), gipakatulog (was told to sleep)

Prefix: gipang-

Definition: a combination of prefixes gi- and pang- that explains something is being done in a way someone commands it

Function: functions as a verb when attached to words
Example: gipangbuy-a,(was being released), gipang-storya (was being spoken)

Prefix: ha-

Definition: used to describe a word in a higher degree Function: functions as an adjective when attached to words Example: hamubo (very short)

Prefix: hi-

Definition: tells something that is intensified; used to command someone

Function: functions as an adjective when attached to words; functions as a verb when attached to words

Example: hilabihan (excellent), higugmaon (love)

Prefix: i-

Definition: used indicate actions that will happen in the future

Function: functions as a verb when attached to words Example: idalit (to offer), itudlo (to point/ teach)

Prefix: ig-

Definition: used to show a relationship

Function: functions as a noun when attached to words

Example: igtagsa (first-degree cousin)

Prefix: ik-

Definition: used to tell that something is done accordingly Function: functions as a noun when attached to words Example: iksakto (timely)

Prefix: ika-

Definition: denotes a numerical order; tells that something can be done possibility

Function: functions as a noun when attached to words; functions as a verb when attached to words 
Example: ikatulo (third); ikabayad (can be paid), ikapalit (can be bought)

Prefix: ikapa-

Definition: a combination of prefixes ika- and pa- that denotes a thing that may or may not happen

Function: functions as a verb when attached to words

Example: ikapakaon (to have something to feed)

Prefix: im-

Definition: equivalent to the English prefixes in-, im-, or unthat only means 'not.'

Function: functions as an adjective when attached to words Example: impossible (not possible)

Prefix: in-

Definition: used to denote similarity or likeness of a thing Function: functions as an adjective when attached to words Example: in-ana (like that), insakto (rightly done)

Prefix: ipa-

Definition: used to express a thing to be accomplished Function: functions as a verb when attached to words Example: ipakaon (to be fed)

Prefix: ka-

Definition: used to connect to an adjective to make a word an abstract noun; denotes camaraderie or partnership Function: functions as a noun when attached to words; functions as a noun when attached to words

Example: kagahi (hardness), kagoul (sadness); kauban (company), kaparehas (same with)

Prefix: kada-

Definition: means 'each' or 'every.'

Function: functions as a pronoun when attached to words Example: kada-adlaw (every day), kadasayop (every mistake)

Prefix: kaga-

Definition: a variant of prefix pagka- that denotes time Function: functions as an adverb when attached to words Example: kagahapon (yesterday)

Prefix: kama-

Definition: used to make an adjective into a noun Function: functions as a noun when attached to words Example: kamatouran (truth)

Prefix: kani-
Definition: used to change a verb into a noun Function: functions as a noun when attached to words Example: kaniadto (ago)

Prefix: kina-

Definition: a variant of pinaka- which is used to express a word in a superlative degree; used to change an adjective into a noun

Function: functions as an adjective when attached to words; functions as a noun when attached to words Example: kinadatuan (richest), kinamagulangan (eldest); kinabuhi (life), kinaadman (wisdom)

Prefix: luma-

Definition: used to change a verb into an adjective Function: functions as an adjective when attached to words Example: lumalabay (temporary)

Prefix: ma-

Definition: denotes possibility that something can be done or indicate a future action

Function: functions as a verb when attached to words Example: maabot (can be reached); maayo (can be fixed)

Prefix: mag-

Definition: denotes an ongoing action that might still happen in the future; used to express a future job/profession

Function: functions as a verb when attached to words Example: mag-ampo (will pray), maghuna-huna (will think); magmaestra (will become a teacher), magpulis (will become a policeman)

Prefix: maga-

Definition: a variant of the prefix mag- that tell a continuing action in the future

Function: functions as a verb when attached to words Example: magatuhaw (will keep on emerging)

Prefix: magka-

Definition: used to show that something can be achieved Function: functions as a noun when attached to words Example: magkahiusa (unity), magkapamilya (family) Prefix: magma- 
Definition: a combination of prefixes mag- and ma- that is used to indicate a possible event in the future

Function: functions as an adjective when attached to words Example: magmalampuson (successful)

Prefix: magpa-

Definition: a combination of prefixes mag- and pa- that is used to change a noun into a verb

Function: functions as a verb when attached to words

Example: magpabilin (stay), magpadayon (continue)

Prefix: magpaka-

Definition: used to refer to an action that is happening continuously

Function: functions as a verb when attached to words

Example: magpakabungol (become deaf)

Prefix: mahi-

Definition: denotes an abstract idea happening; used to refer to a possible condition

Function: functions as a verb when attached to words

Example: mahigugmaon (is loving); mahitungod (is about)

Prefix: maka-

Definition: denotes a future tense or a possible event in the future; tells a reason why something will happen

Function: functions as a verb when attached to words

Example: makaapektar (will affect), makasulay (will try); makadaot (can cause danger), maka-eskwela (can go to school)

Prefix: makapa-

Definition: a combination of maka- and pa- that shows the effect of an action that has been done

Function: functions as a verb when attached to words

Example: makapagawas (express feelings/ideas)

Prefix: makig-

Definition: indicates a desire to perform something for the benefit of someone

Function: functions as a verb when attached to words Example: makighimamat (will meet people), makiglambigit (will engage with others)

Prefix: mama-
Definition: the prefix ma- is repeated once to expresses conclusive action in the future

Function: functions as a verb when attached to words Example: mamahimo (will surely be)

Prefix: mang-

Definition: denotes an action that is yet to be performed

Function: functions as a verb when attached to words

Example: maglaba (will wash), manglimpyo (will clean)

Prefix: mapa-

Definition: a combination of ma- and pa- that expresses a process in doing something

Function: functions as a verb when attached to words

Example: mapakita (to show), mapasalamaton (be thankful)

Prefix: matag-

Definition: used to refer to 'every."

Function: functions as a pronoun when attached to words Example: matag-adlaw (every day), matag-problema (every problem)

Prefix: mi-

Definition: can be referred to as a past or present perfect tense that is used in an active voice

Function: functions as a verb when attached to words

Example: mihukom (judge or judges), mitou (believe or believes)

Prefix: mu-

Definition: can be either spelled as mo- and used to express future action

Function: functions as a verb when attached to words

Example: muhatag (will give); muhunong (will stop)

Prefix: mupa-

Definition: a combination of prefixes mu- and pa- which is used to either a direction to an action to be done Function: functions as a verb when attached to words Example: mupadayon (will continue something)

Prefix: na-

Definition: tells that an action is completed, past tense of ma-; tells a condition of something

Function: functions as a verb when attached to words Example: nahimo (created), nakasulod (entered); nalipay (became happy),napuno (became full) 
Prefix: nag-

Definition: denotes present progressive tense

Function: functions as a verb when attached to words

Example: nag-away (fighting); nagtrabaho (working)

Prefix: naga-

Definition: variant of nag- that tells a continuing action

Function: functions as a verb when attached to words

Example: nagakamang (crawling); nagakinang (shining)

Prefix: nagka-

Definition: the past tense of magka- that indicates something is slowly or increasingly happening

Function: functions as a verb when attached to words

Example: nagagulang (becoming older); nagkadaiyang (getting separated)

Prefix: nagpa-

Definition: the past tense of magpa- that explains why such action is done

Function: functions as a verb when attached to words

Example: nagpakabuta (let oneself not see the situation); nagpasalamat (gave thanks)

Prefix: nahi-

Definition: the past tense of mahi- that explains an expected action or situation

Function: functions as a verb when attached to words

Example: nahibal-an (already knew that something would happen), nahi-uyunan (already agreed)

Prefix: naka-

Definition: the past tense of maka- that denotes a completed action by someone that can do something; tells a reason why something happened

Function: functions as a verb when attached to words

Example: nakaingon (was able to tell), nakasinati (was able to experience); nakahuman (had finished), nakasabot (had understood)

Prefix: nang-

Definition: past tense of $\mathbf{m a n g}$ - that denotes a completed action

Function: functions as a verb when attached to words

Example: nangandoy (wised), nanghinaot (hoped)

Prefix: naning-

Definition: a combination of na- which denotes a complete action and ning- which indicates a capability to do something; at present, the prefix 'naning' has been used separately to refer to a hardworking individual

Function: functions as a verb when attached to words
Example: naningkamot (sought to provide something); naningtiil (continued doing something to earn a living)

Prefix: ni-

Definition: a variant of $\mathbf{m i -}$, however, this only refers to a past action and is usually used in ordinary conversation Function: functions as a verb when attached to words Example: niabot (reached), nisalig (trusted)

Prefix: ning-

Definition: the past tense of mang- that indicates a capability to do something; or the action is already done Function: functions as a verb when attached to words Example: ninglangyaw (traveled), ningsuporta (supported)

Prefix: pa-

Definition: tells a direction or a process of a specific action of the root verb

Function: functions as a verb when attached to words Example: paminaw (going to pay attention/ listen to someone), pawala (going to the left side)

Prefix: pag-

Definition: tells a command or direction; can be used to represent an infinitive phrase; tells a condition or a situation Function: functions as a verb when attached to words; functions as a verb when attached to words; functions as a noun when attached to words

Example: paglaba (you wash), pagluto (you cook); pagbasa (to read), pagtoun (to study); pag-ayo (tells how something is being fixed), pagbiya (a situation of leaving someone or something

Prefix: pag-

Definition: can be used as a verb into a noun; indicates the word 'when' and used to refer to past events

Function: functions as a noun when attached to words; functions as a pronoun when attached to words

Example: pagpili (choice), pagsulay (test or trial); pag-grade 10 (when somebody was in grade 10), pagsenior high school (when someone was still a senior high school student)

Prefix: paga-

Definition: a variant of pag- that denotes a present action that will still be acted in the future

Function: functions as a verb when attached to words Example: pagaampingan (will be taken good care of), pagasubaybayon (will be monitored)

Prefix: paghi-

Definition: a combination of pag- and hi- that denotes an abstract situation

Function: functions as a noun when attached to words Example: paghigugma (love) 
Prefix: pagka-

Definition: prefixes pag- and ka- are combined to produce a surprising statement; explains an act or process of something

Function: functions as a noun when attached to words Example: pagkaaninidot (how beautiful), pagkadaghan (how many or plenty); pagkakaron (for now), pagkatawo (becoming human)

Prefix: pagpa-

Definition: indicates a sympathetic way or act of doing something

Function: functions as a verb when attached to words

Example: pagpakabuhi (an act of living); pagpalangga (act to loving)

Prefix: pakig-

Definition: used to establish a relationship with someone or to make decisions

Function: functions as a verb when attached to words Example: pakighigalaay (to make friends with others), pakighimamat (to engage with other people)

Prefix: pama-

Definition: a variant of pam- or pang- that tell a particular use or condition of something

Function: functions as a verb when attached to words

Example: pamaagi (way of doing)

Prefix: pang-

Definition: used to represent a specific usage of a noun or pronoun; used to make a command or direction

Function: functions as an adjective when attached to words; functions as a verb when attached to words Example: pangbalay (for the household), panglawas (for health); pangarte (have adornment or be creative), panguyab (have a boyfriend/girlfriend)

Prefix: pasi-

Definition: used to make a concrete noun into an abstract idea

Function: functions as a noun when attached to words

Example: pasidunggan (honor)

Prefix: pi-

Definition: used only for emphasis

Function: functions as an adjective when attached to words
Example: pipila (only a few)

Prefix: pina-

Definition: denotes a particular process

Function: functions as an adverb when attached to words Example: pinalangga (dearly), pinaagi (through)

Prefix: pinaka-

Definition: used to describe an adjective in the superlative degree

Function: functions as an adjective when attached to words Example: pinakadako (biggest), pinakaganahan (likest)

Prefix: ra-

Definition: Indicates that a thing is in its simplest form Function: functions as an adjective when attached to words Example: raman (only this)

Prefix: su-

Definition: used to explain a manner how things are made or done

Function: functions as an adverb when attached to words Example: susama (similarly)

Prefix: tag-

Definition: can be used to refer to a quantity of a thing or a task to be performed by someone

Function: functions as an adjective when attached to words Example: tagsa-tagsa (one by one)

Prefix: ti-

Definition: usually added to a root noun to describe a word Function: functions as an adjective when attached to words Example: tibouk (whole), tiunay (genuine)

Prefix: tig-

Definition: denotes a responsibility or fondness that one should always perform

Function: functions as a noun when attached to words Example: tighugas (the ones responsible for washing something), tiglung-ag (the one responsible for cooking rice)

Prefix: uma-

Definition: indicates future event or activity

Function: functions as a verb when attached to words

Example: umaabot (expected to come or happen) 
As observed from the presented data, most of the prefixes in the Guihulngan-Visayan language function as a verb that denotes past, present, and future tenses. The past tense is usually in the form of $\mathbf{g i -}$, ni-, nag-, and some other prefixes which tell that action is already completed. The present or present progressive tense (both can be used depending on the speaker), like gina-, gipang-, or mi- that express a continuous action. It can also be noted that there is no need to use the modal 'will' because prefixes mu- and mag- already express futurity. The superlative degree of an adjective, usually in the form of -est, is used in Guihulngan-Visayan as a prefix in the form of kina- or pinaka-, thus, the presence of inflectional morphemes are seldom used. In Naseeb \& Ibrahim (2017), the analysis will clarify why derivations can induce inflecting but not vice versa. The distinction between derivative and inflection is this. Derivation relies not on inflexive finishes but the stem shapes of the words. So new complex stems may be used with inflexible laws. The disparity between the morphology of inflections and the morphology of derivatives is ancient. It is a question of constructing new lexemes and mark lexemes for a given sentence (derivative applies, among other processes).

\section{B.2. Meaning and Functions of Infixes}

Infixes have also shown interesting part of the language as it allows the speakers to use varied forms of sending communication, creating an impact on making interactions. The infixes used in the corpus are as follows:

Infix: -hi-

Definition: denotes an intangible object, event, or idea

Function: dependents on the root word

Example: naghigugmamaay (loving); nahisaag (is lost)

Infix: -in-

Definition: expresses a manner based on the root word

Function: dependents on the root word

Example: binuang (joke); magtinabangay (help each other)

Infix: -la-

Definition: used to modify the expression of the root word

Function: dependents on the root word

Example: salaputon (one who quickly gets mad)
Infix: -lu-

Definition: usually placed in the second syllable to add emphasis to the word

Function: dependents on the root word

Example: buluhaton (series of activities)

Infix: -um-

Definition: usually found after the first letter of the root word to make a present continuing statement

Function: dependents on the root word

Example: gumikan (because of); sumusunod (following upon)

There are only a few derivational morphemes used as infixes that were identified based on the corpus. This also reveals that these infixes do not have a particular function. They are dependent on the root word, and the meaning may vary based on its usage. The word 'binuang,' for example, is composed of two morphemes, buang (crazy) + in (placed after the first letter), making the word a noun from an adjective (based on the stem). The infix -um- can also make a significant shift of a word, gikan (from) + um (placed after the first letter), creates other parts of speech which are conjunction. Thus it is tough to predict a particular function of the infix. The Infixation analysis of Beljan (2015) is much more versatile and not exclusively prone to many guidelines than some other morphological processes. While it is still a somewhat complicated operation, in general, the morphological system of the Guihulngan-Visayan or Cebuano can now be found more straightforward as before all the incremental improvements in the system.

\section{B.3. Meaning and Functions of Suffixes}

The identified suffixes articulate that the language is composed of different word usages that one must be familiar with to achieve effective communication. The suffixes found in the corpus are as follows:

Suffix: -a

Definition: expresses a command or request; used to show possession; used to describe an object

Function: functions as a verb when attached to words; functions as a pronoun when attached to words; functions as an adjective when attached to words
Example: lantawa (look at it), paninawa (listen to it); akoa (mine), amoa (ours); kalibutana (this world), panahona (this time)

Suffix: -an

Definition: denotes an action to be given to someone Function: functions as a verb when attached to words Example: ampingan (give care), gabayan (give guidance) 
Suffix: -anan

Definition: usually attached to a word ending with a consonant that shifts a verb into a noun

Function: functions as a pronoun when attached to words Example: baruganan (principles)

Suffix: -ang

Definition: a combination of suffixes -a and -ng, which describes the word that follows, and it is usually attached to a root word with a vowel ending

Function: functions as a pronoun when attached to words Example: akoang (my __), amoang (our___)

Suffix: -ay

Definition: indicates that the action is still ongoing; however, the root verb functions as a noun when this suffix is used

Function: functions as a noun when attached to words

Example: paggunitay (holding), magtinabangay (helping)

Suffix: $-g$

Definition: a shortened form of the word 'ug' (and) which is used to link or connect the suffixed word to the following word

Function: functions as a conjunction when attached to words

Example: siyag (he and), akog (me and)

Suffix: $-g$

Definition: when a word already ends with ' $n$,' the suffix is added that means there is something

Function: functions as a conjunction when attached to words

Example: arong (so that), tanang (all that)

Suffix: -ha

Definition: denotes that someone owns something

Function: functions as a pronoun when attached to words

Example: iyaha (his or hers), imuha (yours)

Suffix: -han

Definition: tells that an action is done in favor of someone; the root verb becomes a noun when this suffix is used; express a situation or condition

Function: dependents on the root word

Example: kagustuhan (preference), kasiguraduhan (security); kaayuhan (better), adunahan (rich)'
Suffix: -i

Definition: tells the command to someone

Function: functions as a verb when attached to words

Example: kalimti (forget it); pasagdai (do not mind it)

Suffix: -ng

Definition: similar to the word 'nga' but as a suffix, it is connected or linked to a root noun root adjective to show the relationship of words

Function: dependents on the root word

Example: lalaking (a boy who is), tawong (a person who is)

\section{Suffix: -nong}

Definition: shows a situation of manner while doing or wanting something

Function: functions as an adverb when attached to words Example: lawanong (bodily), unodnong (fleshly)

Suffix: -on

Definition: a variant of hon- that tells an intangible thing, idea, or action

Function: dependents on the root word

Example: lig-onon (strengthen), malinawon (tranquil)

Suffix: -ong

Definition: combination of suffixes -on and $\mathbf{- g}$ that is used to describe a noun or pronoun

Function: functions as an adjective when attached to words Example: mabugnawong (a cold), mapinalanggaong (a loving)

Suffix: -s

Definition: equivalent to the word 'sa', which is used to indicate a place

Function: dependents on the root word

Example: nakos (in my)

Suffix: -so

Definition: used to tell a behavior of a male person, animal, or thing; the suffix -sa is typically used for female

Function: functions as an adjective when attached to words Example: misteryoso (a mysterious guy)

Suffix: $-y$ 
Definition: equivalent to the copula 'is' that is generally used as a subject of a Visayan sentence
Function: dependents on the root word

Example: unsay (what is), adunay (there is)

The result shows the function of the different use of suffixes that were used in the corpus. It can be seen that most of them carry the function of their root word. When added with the suffix, the word 'lantaw' (look), when added with the suffix -a becomes 'lantawa' (look at it) that directs someone to follow a command. There are also instances where suffixes could tell a gender, like misteryoso (a mysterious guy) or tsismosa (a girl fond of telling gossip). Another thing that makes this suffix unique is its function as a word connection, e.g., siyag ako (he and me). The suffix $-\mathrm{g}$ is attached to a word that links it to another word.

Furthermore, it can be used to replace the English copula 'is,' e.g., unsa (what) + -y will make the word unsay (what is). However, we cannot generalize this derivational morpheme's particular function because meanings may vary as the language speaker uses it. Thus, the process may become dependent on the speaker. Ibrahim \& Naseeb (2017) found that the morphological mechanism can also be based on the conceptual basis on which derived words form an individual lexical entity inserted in a speech dictionary on their own. Sometimes they have a specific sensation over time that cannot be anticipated fully in the components' morphemes. At times, students starting the type of foundation on which an apple is added have difficulties.

\section{Conclusion}

The two objectives of the study were properly addressed: What are the different derivational morphemes used in Guihulngan Visayan based on the essays? What are the meanings and functions of each derivational morpheme? The study shows that $70.31 \%$ of the derivational morphemes were used as prefixes, $2.39 \%$ were identified as infixes, and $27.30 \%$ were suffixes that explain that the language has varying purposes that one must discover. Furthermore, the meanings and functions of derivational morphemes do not actually show definite use, since words can be utilized in different aspects depending on the prior knowledge of the speaker.

The researcher would like to conclude that the derivation morphemes of the Guihulngan-Visayan involve several thrilling morphological processes that can impact a speaker's messages. This analysis involved an extensive examination of the derivation morphemes in the corpus and that construction morphology 'is divided between grammar and lexicon.' The terms in GuihulnganVisayan were used differently: prefixes are often used to tell the verb tense, infixes are dependent on the stem or the root word, and suffixes are usually used to make words as adjectives. However, this does not entail that all affixes have the same morphological process. The problem of committing errors in derivative morphemes was clarified by the studied Irahim \& Naseeb (2017). It is a cumulative issue that arises from other problems faced by the speakers concerning the trunk. Hence, understanding the language must be a required precondition for comprehending and proficient in the Cebuano language, particularly its morphology.

The study contributes deeper and comprehensive understanding of the Visayan language, as this specifies the individual uses and functions of derivational morphemes. Oftentimes, speakers may use different morphemes based on their present ideas or concepts, but do not take into consideration the proper use of the language, thus misunderstanding occurs. On the other hand, the researcher acknowledgeds that this resources for this study is too limited to derivational morphemes, which are found in the corpus made by the students. Thus, this only focuses on and discusses the different morphemes used as prefixes, infixes, and suffixes in Guihulngan-Visayan, even the Cebuano as the primary language in the Visayan region. Language experts should also investigate other kinds of derived morphemes. It will improve Visayan grammar and develop expertise in studying the morphological process in cooperation.

Acknowledgements: The author expresses gratitude to the major in English students for voluntary participation in the study and the administrators of Negros Oriental State University for allowing the researcher to realize this research endeavor.

Conflicts of Interest: The author declares no conflict of interest.

\section{References}

[1] Abid, M., Sultan, B., Asif, M., Rafique, N., \& Aleem, S. (2020). An Analysis of Derivational and Inflectional Morphemes. International Journal of Linguistics, 20.

[2] Beljan, M. (2015). Infixation in English varieties over the world (Final thesis). Retrieved from https://urn.nsk.hr/urn:nbn:hr:142:892187

[3] Bodily, J., \& Lonsdale, D. (2014). Morphologically Parsing Cebuano Lexicon. Journal of Undergraduate Research.

[4] Booij, G. (2017). Construction Morphology. Oxford Research Encyclopedia. Cognitove Science: A Multidiciplinary Journal.

[5] Firat, I. (2006). Ways of Creating Prefixes and Suffixes and Foreign Language Teaching. Journal of Language and Linguistic Studies

[6] Ibrahim, M., \& Naseeb, M. Z. (2017). Morphological Derivations: Learning Difficulties Encountered by. English Language Teaching, 10. 